\title{
Obtención de una sonda para cuantificar el mARN del factor activador de la transcripción STAT5 en rata
}

\author{
Blanca L. Ortiz ${ }^{1}$, Myriam Sánchez de Gómez ${ }^{1}$, Gunnar Norstedt ${ }^{2}$
}

\begin{abstract}
Resumen
Se describe la estrategia empleada para clonar, en un vector de expresión, un fragmento del gen de STAT5 amplificado por la técnica de PCR. Variando la concentración de magnesio y la temperatura de alineación, se logró amplificar el fragmento deseado a partir de un cADN de STAT5b de ratón. El producto de PCR se clonó y se comprobó la identidad de la sonda mediante análisis de restricción y secuenciación.
\end{abstract}

Esta sonda se usó en el ensayo de protección con ribonucleasa A o hibridización en solución, para cuantificar el mARN de STAT5 en hígado y linfocitos de timo de ratas hembras. Se encontró una mayor expresión del mARN de STAT5 en hígado.

\section{A new probe for use in quantifying STAT5 transcription activator factor in rat mRNA.}

The strategy for cloning a PCR-amplified STAT5 fragment into an expression vector is described. By optimising the magnesium level and the annealing temperature in the PCR reaction, target fragment amplification was achieved, using mouse STAT5b cDNA as a template. The PCR product was cloned and probe identity was confirmed by restriction analysis and sequencing.

This probe was used in a solution hybridisation-Rnase protection assay to quantify STAT5 mRNA in female rats' livers and thymus lymphocytes. A higher STAT5 mRNA expression was found in liver.

La unión de un ligando a su receptor inicia una cascada de eventos intracelularmente, los cuales modulan varias funciones celulares entre las que se incluye el control de la expresión genética. Alterando el espectro de genes expresados, la célula modifica apropiadamente su fisiología ante un estímulo dado. La hormona de crecimiento $(\mathrm{GH})$ ejerce sus múltiples acciones biológicas interactuando con sus receptores localizados en la membrana de la célula blanco, lo cual provoca la dimerización del receptor y la asociación con JAK2, una proteína de la familia Janus, de tirosina cinasas. Esta asociación induce la fosforilación de la cinasa, la fosforilación del receptor mismo y la fosforilación en tirosina de proteínas citosólicas que incluyen a miembros del la familia STAT (transductores de señales y activadores de la Transcripción). Las moléculas fosforiladas de STAT se dimerizan y migran al núcleo donde se unen a elementos de respuesta en el ADN, activando así la transcripción de genes específicos (1).

\footnotetext{
1 Departamento de Química, Facultad de Ciencias, Universidad Nacional de Colombia, Santa Fe de Bogotá, Colombia.

2 Departamento de Medicina Molecular, Instituto Karolinska, Estocolmo, Suecia.

Recibido para su publicación: 1 de junio de 1998 - Aprobado para su publicación: 19 de agosto de 1998
} 
Hasta el momento se han clonado ocho proteínas STAT: STAT $1 \alpha$, STAT $1 \beta$, STAT2, STAT3, STAT4, STAT5, STAT6 y una STAT de Drosophila (2). De STAT5, se han identificado dos isoformas denominadas STAT5a y STAT5b (3). Las proteínas STAT constan de 5 dominios funcionales: un dominio amino-terminal, un dominio de unión al ADN, un dominio $\mathrm{SH} 2$, un dominio $\mathrm{SH} 3$ y un dominio carboxilo-terminal. Con base en secuencias informadas para los cADN y comparación de secuencias de las proteínas STAT (3), se amplificó por la técnica de reacción en cadena de la polimerasa (PCR) (4), una región en el extremo 5' del CADN de STAT5b de ratón (secuencia blanco), por ser una de las zonas en que divergen las secuencias de STAT1, STAT3 y STAT5 que son las activadas por $\mathrm{GH}$ en ratas (5).

En este trabajo se describe la clonación del producto amplificado, la comprobación de su identidad y la utilización de la sonda obtenida en la cuantificación de la expresión del gen de STAT5 en hígado y en linfocitos de timo de rata.

\section{Materiales y Métodos}

\section{Animales}

Se utilizaron 4 ratas hembras Wistar de 7 semanas de edad y peso promedio de $155 \mathrm{~g}$, suministradas por el bioterio del Instituto Nacional de Salud (INS) y mantenidas allí en condiciones controladas de luz (12-h luz, 12-h oscuridad) y temperatura $\left(21^{\circ} \mathrm{C}\right)$, y con libre acceso al alimento y al agua.

Después de un período de adaptación de 7 días, los animales fueron sacrificados por asfixia en cámara de $\mathrm{CO}_{2}$ y se removieron el hígado y el timo los cuales se congelaron inmediatamente en $\mathrm{N}_{2}$ líquido y, luego, se mantuvieron a $-70^{\circ} \mathrm{C}$.

\section{Separación de linfocitos de tímo}

La separación de los linfocitos de timo se realizó por gradiente de Percoll (Pharmacia) $\mathrm{d}=1,07 \mathrm{~g} / \mathrm{ml}$.

\section{Extraccion y cuantificación de ácidos nucleicos}

La extracción de ARN total y de ADN de hígado y de linfocitos de timo se realizó empleando el reactivo trizol (Life Technologies), el cual es un mejoramiento del método de Chomczynski y Sacchi (6), que permite aislar RNA total, DNA y proteínas de células y tejidos. Las muestras extraidas se almacenaron a $-70^{\circ} \mathrm{C}$ hasta el momento del análisis.

Las concentraciones de ARN total se determinaron espectrofotométricamente y el contenido de ADN se midió utilizando el método fluorométrico de Labarca y Paigen (7), empleando una curva de calibración realizada con patrón de ADN de timo de ternera (50-1000 $\mathrm{ng} / \mathrm{mL}$ ) y una concentración de bisbenzimida de $1 \mu \mathrm{g} / \mathrm{mL}$ y lecturas en un fluorómetro PerkinElmer, modelo LS-3B.

\section{Amplificación por PCR}

\section{Síntesis de los oligonucleótidos iniciadores}

Al momento de realizar este trabajo, sólo se disponía del cADN de STAT5b de ratón, por lo tanto se empleó la secuencia publicada de este cADN (3), para diseñar los oligonucleótidos iniciadores o primers. La secuencia del oligonucleótido sentido (primer 5') es :

5'-GGGACTCAATAGATCTTGATAATCC-3' (sitio de corte con la enzima $\mathrm{Bgl}$ II, subrayado).

La secuencia del oligonucleótido antisentido (primer 3') es :

5'-AACTGAGCTTGGATCCGCAGGCTCT-3' (sitio de corte con la enzima Bam HI, subrayado).

La síntesis de los oligonucleótidos se realizó empleando el sistema Oligo Pilot I/ DNA/RNA Synthesizer de Pharmacia __aboratories.

\section{Estandarización de la técnica de PCR}

Los ensayos se realizaron con base en el protocolo sugerido por New England Biolabs Inc. (Technical Bulletin 2/21/95). Se partió de un cADN de STAT5b de ratón suministrado por DNAX-Research Institute of Molecular and Cellular Biology Inc. Se ensayaron concentraciones finales de $\mathrm{MgSO}_{4}$ de $3 \mathrm{mM}$ y $4 \mathrm{mM}$ y temperaturas de alineación de 55,60 y $65^{\circ} \mathrm{C}$.

Se empleó un termociclador Techme Labasco Analysis PHC-3, con el siguiente programa : 
Un ciclo: denaturación inicial a $95^{\circ} \mathrm{C} / 3 \mathrm{~min}$, alineación a $55,60 \circ 65^{\circ} \mathrm{C} / 2$ min y extensión a $75^{\circ} \mathrm{C} / 2 \mathrm{~min}$. 25 ciclos: denaturación a $94^{\circ} \mathrm{C} / 1$ min, alineación a $55,60 \circ 65^{\circ} \mathrm{C} / 1 \mathrm{~min}$ y extensión a $75^{\circ} \mathrm{C} / 1 \mathrm{~min}$. Un ciclo: extensión a $72^{\circ} \mathrm{C} / 7 \mathrm{~min}$.

Finalizado el proceso, se corrieron $10 \mu \mathrm{l}$ de cada mezcla de reacción en un gel de agarosa al $1 \%$, bromuro de etidio $0,5 \mu \mathrm{g} / \mathrm{ml}$ y buffer $\mathrm{TAE}$ (tris-acetato $40 \mathrm{mM}$, EDTA $1 \mathrm{mM}, \mathrm{pH} \mathrm{8,0),}$ durante una hora a 100 voltios. Los productos ampli-ficados se observaron con transiluminador de luz ultravioleta y la imagen se captó con una cámara polaroid. El resto del volumen de reacción se purificó utilizando el kit de Promega Wizard PCR Preps. (Promega, Technical Bulletin No. 118).

\section{Clonación del producto de PCR}

Se empleó el vector pGEM -7Zf (+) que contiene el gen de resistencia a la ampicilina y el gen lac $Z$ que codifica para parte de la enzima fosforiladas $\beta$-galactosidasa.

\section{Digestión con las enzimas de restricción Bam HI y Bgl II y Ligación.}

EI vector pGEM-7Z $(2 \mu \mathrm{g})$ se digirió con la enzima Bam $\mathrm{HI}$, se defosforiló con fosfatasa alcalina de intestino de ternera (CIP, $2 \mathrm{U}$ ), y se purificó por electroforesis en gel de agarosa al $1 \%$, con bromuro de etidio $0,5 \mu \mathrm{g} / \mathrm{mL}$, en buffer TAE. La banda correspondiente al vector se cortó del gel y se purificó en una columna Ultra free-MC Filter Unit (Millipore), de donde se recuperó el vector por centrifugación a $5.000 \times \mathrm{g}$ durante 20 minutos. El producto de la reacción de PCR o fragmento de STAT5 se sometió a digestión con las enzimas Bgl II y Bam $\mathrm{HI}$ que generan extremos complementarios. Se purificó por electroforesis en gel de agarosa al $1 \%$, con bromuro de etidio $0,5 \mu \mathrm{g} / \mathrm{mL}$, en buffer TAE. La banda correspondiente al fragmento de $430 \mathrm{pb}$ se cortó del gel y se purificó de la misma manera descrita para el vector.

El vector $\mathrm{pGEM}-7 \mathrm{Z} / \mathrm{Bam} \mathrm{HI}$ y el fragmento STAT5 Bgl II/Bam HI se mezclaron en diferentes relaciones molares. Inserto: vector $(0: 1,5: 1$, $10: 1$ y $40: 1$ ), se trataron con T4 ADN ligasa, y se incubó a $16^{\circ} \mathrm{C}$ durante la noche.

\section{Transformación y selección de transformantes}

Con el producto ligado se transformaron bacterias JM-83 de E.coli y se seleccionaron los transformantes adicionando en el medio sólido de cultivo, IPTG ( $8 \mathrm{ml}$ de una solución $0,5 \mathrm{M}$ ), inductor de la enzima $\beta$-galactosidasa y X-gal (100 mL de una solución al $2 \%$ en dimetilformamida), un análogo de la lactosa que por acción de la $\beta$-galactosidasa da un producto de color azul. Las colonias recombinantes con un gen lac $\mathrm{Z}$ interrumpido no sintetizarán $\beta$ galactosidasa y darán colonias blancas.

Algunas de las colonias blancas presentes fueron reinoculadas individualmente en medio LB líquido con ampicilina $(100 \mu \mathrm{g} / \mathrm{ml})$ para realizar la extracción del ADN plasmídico empleando el kit QIAprep Spin (QIAGEN Inc.).

\section{Identificación del producto clonado}

\section{Análisis de restricción del DNA plasmídico y secuenciación}

Para determinar si los plásmidos extraidos contenían o no el inserto deseado, éstos fueron tratados con la enzima de restricción $\mathrm{Nco}$ I con sitio de corte únicamente en el inserto, de tal manera que si hubo inserción generará un solo fragmento de $3430 \mathrm{pb}$. Además, se hizo tratamiento con la enzima Sca I que tiene un sitio de corte en el vector y un sitio de corte en el inserto, de tal manera que si hubo inserción generará dos fragmentos de 1849 y 1581 pb que indicarán, así mismo, una inserción en el marco de lectura. Si los fragmentos son de 2169 y $1261 \mathrm{pb}$ la inserción habrá sido invertida.

El producto clonado se secuenció, usando el sistema automático $\mathrm{ABI} 373 \mathrm{~A} A D N$ Sequencing System.

\section{Cuantificación del mARN de STAT5 en tejidos de rata}

\section{Transcripción in vitro}

Con el propósito de sintetizar las ribosondas sentido y antisentido, se procedió a transcribir in vitro la sonda o producto clonado, siguiendo un protocolo adaptado de Promega (Promega Corporation, 1991). Para la síntesis de la ribo- 
sonda antisentido, la sonda de STAT5 se linearizó con la enzima Eco RI, se separó del plásmido no linearizado por electroforesis en gel de agarosa y se extrajo según el método descrito por Lau y Sheu (8). Aproximadamente $10 \mathrm{mg}$ de este CADN plantilla se transcribieron in vitro con SP6 ARN polimerasa $(6 \mathrm{U} / \mu \mathrm{g}$ de ADN) en presencia de ${ }^{35} \mathrm{~S}$-UTP (actividad específica $1.000 \mathrm{Ci} / \mathrm{mmol}$, Amersham) incubando por $90 \mathrm{~min}$ a $40^{\circ} \mathrm{C}$. Luego de una extracción con fenol/cloroformo, los nucleótidos no incorporados se removieron por fraccionamiento a través de una columna Nick empacada con Sephadex G-50 (Pharmacia) y la actividad específica se determinó por precipitación con ácido tricloroacético (TCA), captura sobre filtros de fibra de vidrio (GF/C, Whatman) y cuantificación en contador de centelleo líquido (Beckman, modelo LS 5000 TD).

Para la síntesis de la cadena de ARN sentido, se siguió el procedimiento antes descrito excepto que la sonda de STAT5 se linearizó con la enzima Mlu I y se transcribió in vitro con T7

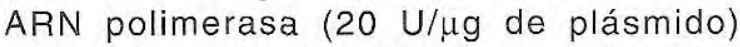
incubando por 90 min a $37^{\circ} \mathrm{C}$. La concentración final de transcrito ARN sentido se determinó espectrofotométricamente. Los transcritos sentido y antisentidos de ARN se dividieron en alícuotas y se almacenaron a $-70^{\circ} \mathrm{C}$ hasta su uso.

\section{Ensayo de protección con ribonucleasa A o hibridización en solución}

Se siguió el método desarrollado por Durnam y Palmiter (9), modificado por Moller (10).

La sonda de ARN antisentido radiomarcada (20.000 cpm) se hibridizó en solución con concentraciones crecientes de sonda de ARN sentido $(0-25 \mathrm{pg})$, para construir la curva patrón o con cantidades variables de las muestras de ARN total de hígado o linfocitos de timo $(10,20$ y $40 \mathrm{mg}$ ). Las hibridizaciones se hicieron por 18 h a $70^{\circ} \mathrm{C}$ en presencia de $25 \%$ de formamida, $0,75 \mathrm{mM}$ DTT, $0,6 \mathrm{M} \mathrm{NaCl}, 20 \mathrm{mM}$ Tris y $4 \mathrm{mM}$ EDTA, en un volumen de reacción de $40 \mathrm{ml}$ cubiertos con aceite de parafina. EI ANR no hibridizado se degradó luego por adición de 1 $\mathrm{mL}$ de ARNasa A $(40 \mu \mathrm{g} / \mathrm{mL})$, ADN de esperma de salmón $(100 \mu \mathrm{g} / \mathrm{ml})$ e incubación a $37^{\circ} \mathrm{C}$ por $45 \mathrm{~min}$. Los híbridos resistentes a la acción de la ribonucleasa se precipitaron por adición de $100 \mu \mathrm{l}$ de TCA 6M e incubación en hielo por 30 min. Los híbridos se capturaron por filtración a través de filtros GF/C, Whatman, se lavaron una vez con TCA al $4 \%$ en pirofosfato de sodio al $1 \%$ y dos veces con etanol al $70 \%$. La a adioactividad hibridizada se midió en un contador de centelleo líquido.

La curva patrón se construyó graficando la radioactividad hibridizada por la ribosonda sentido, cpm hibridizadas, contra las concentraciones crecientes de dicha ribosonda de ARN sentido expresadas en picogramos $(\mathrm{pg})$. Finalmente, los resultados se expresaron como

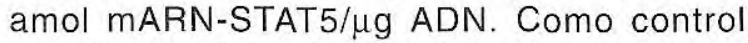
negativo se hibridizó tARN (10 y $20 \mu \mathrm{g})$.

\section{Resultados}

\section{Amplificación por PCR}

Para la amplificación por PCR, se optimizaron las condiciones de reacción con respecto a la concentración de $\mathrm{MgSO}_{4}$ y la temperatura de alineación. En la figura 1 podemos observar la electroforesis de los productos obtenidos, en todos los casos se amplifica el fragmento esperado de $430 \mathrm{pb}$, pero, además, aparecieron

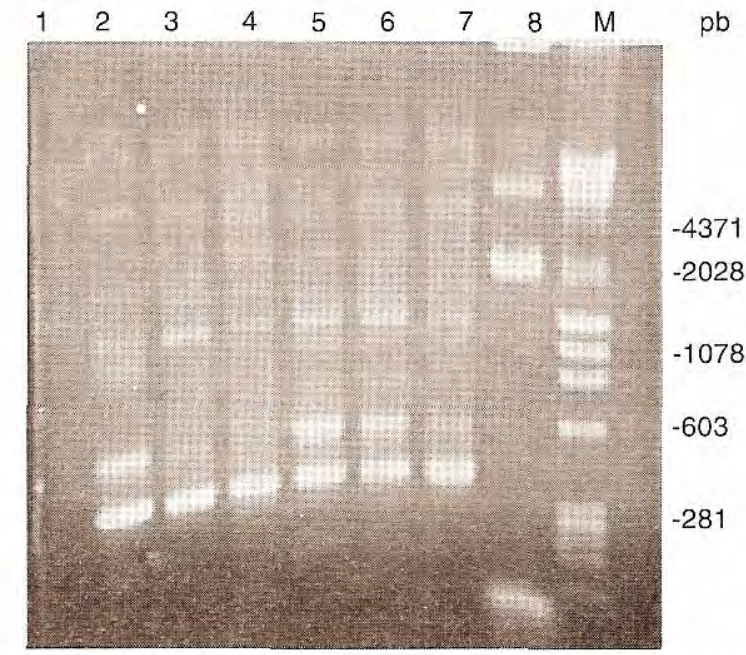

Figura 1. Resultado de la optimización del PCR. Control Negativo (1); PCR con $4 \mathrm{mM} \mathrm{MgSO}_{4}$ : alineación a $55^{\circ} \mathrm{C}$ (2), a $60^{\circ} \mathrm{C}(3)$, a $65^{\circ} \mathrm{C}(4)$; PCR con $3 \mathrm{mM} \mathrm{MgSO}_{4}$ : Alineación a $55^{\circ} \mathrm{C}(5)$, a $60^{\circ} \mathrm{C}(6)$, a $65^{\circ} \mathrm{C}(7)$; pGEM-7Z sin digerir (8), Marcador de tamaño lambda/ Hindlll/fx-174/Haelll (M). 
otros productos de reacción que fueron mínimos empleando las condiciones de $4 \mathrm{mM}$ de $\mathrm{MgSO}_{4}$ y alineación a $65^{\circ} \mathrm{C}$ (carril 4). Por tanto, el producto amplificado en estas condiciones se escogió para hacer la clonación.

\section{Clonación del producto amplificado}

Siguiendo el procedimiento descrito en materiales y métodos, se obtuvieron colonias blancas en las transformaciones con los productos de ligación correspondientes a las relaciones inserto-vector 10:1 y 40:1. Se hicieron las minipreparaciones que se denominaron: clones $\mathrm{J}_{21}-\mathrm{J}_{22}-\mathrm{J}_{23}-\mathrm{J}_{24}$ (inserto: vector 10:1) y clones $J_{31}-J_{32}-J_{33}$ (inserto: vector $40: 1)$

\section{Identificación del producto clonado}

\section{Análisis de restricción y secuenciación}

El resultado mostró que los clones $J_{33}$ y $J_{31}$ (figura 2, carriles 4 y 6 ) se linearizan al ser digeridos con la enzima Nco I y se obtiene la banda esperada de 3430 pb. Los demás plásmidos no contienen el inserto.

Con el ánimo de confirmar la presencia del inserto y establecer además su orientación, se

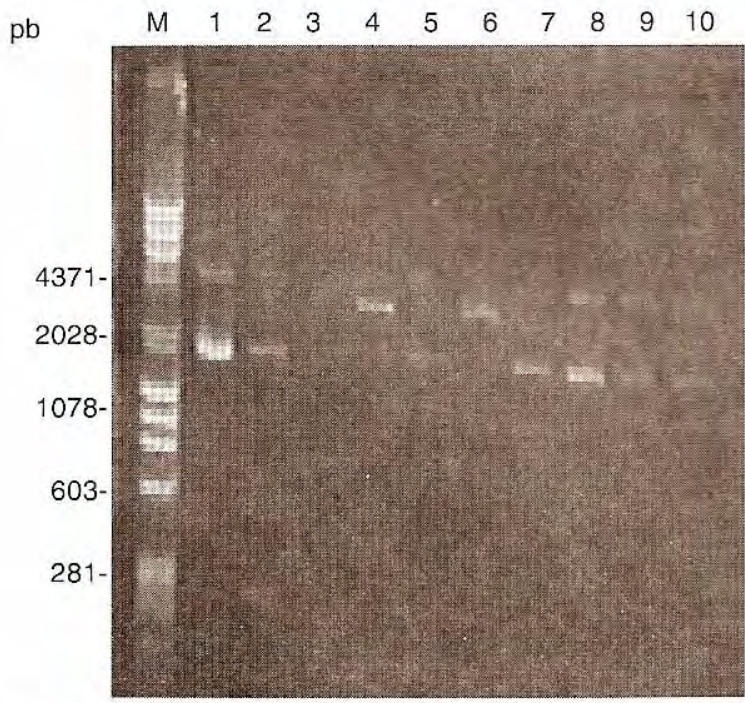

Figura 2. Análisis de restricción, corte con Nco I. Marcador de tamaño (M); pGEM-7Z no digerido (1), pGEM$7 Z / \mathrm{Nco} I$ (2), producto de PCR/Nco I (3), clon $\mathrm{J}_{33} / \mathrm{Nco} \mathrm{I} \mathrm{(4),}$ clon $\mathrm{J}_{32} / \mathrm{NcO} I$ ( 5 ), clon $\mathrm{J}_{31} / \mathrm{NcO}$ I (6), clon $\mathrm{J}_{24} / \mathrm{NcO}$ I (7), clon $\mathrm{J}_{23} / \mathrm{NcO}$ I (8), clon $\mathrm{J}_{22} / \mathrm{NcO}$ I (9), clon $\mathrm{J}_{21} / \mathrm{Nco} \mathrm{I} \mathrm{(10).}$ hizo la digestión de los clones $\mathrm{J}_{33}$ y $\mathrm{J}_{31}$ con la enzima de restricción Sca I y, tal como se muestra en la figura 3 , con el clon $J_{31}$ (carril 4) no se obtuvo buen resultado mientras que con el clon $\mathrm{J}_{33}$ (carril 3) se obtuvieron las dos bandas esperadas, las cuales resultaron ser de 1849 y $1541 \mathrm{pb}$ que indican una inserción en la dirección del marco de lectura.

Para demostrar si el inserto tenía la secuencia correcta, se secuenció el clon $\mathrm{J}_{33}$. La secuencia de la sonda obtenida alineada con la secuencia informada para el fragmento correspondiente del cADN de STAT5 b de ratón resultó completamente idéntica (resultado no mostrado).

\section{Cuantificación del mRNA de STAT5 en tejidos de rata}

En la transcripción in vitro, se obtuvo una ribosonda antisentido con actividad específica de $1,1 \times 10^{9} \mathrm{cpm} / \mu \mathrm{g}$. Hibridizando en solución esta ribosonda antisentido marcada con cantidades conocidas $(0-25 \mathrm{pg})$ de patrón de ribosonda sentido, se obtuvo la curva típica dosis-respuesta o curva patrón que se muestra en la figura 4.

En el cuadro 1 se muestran los resultados de la cuantificación de mARN de STAT5 en las

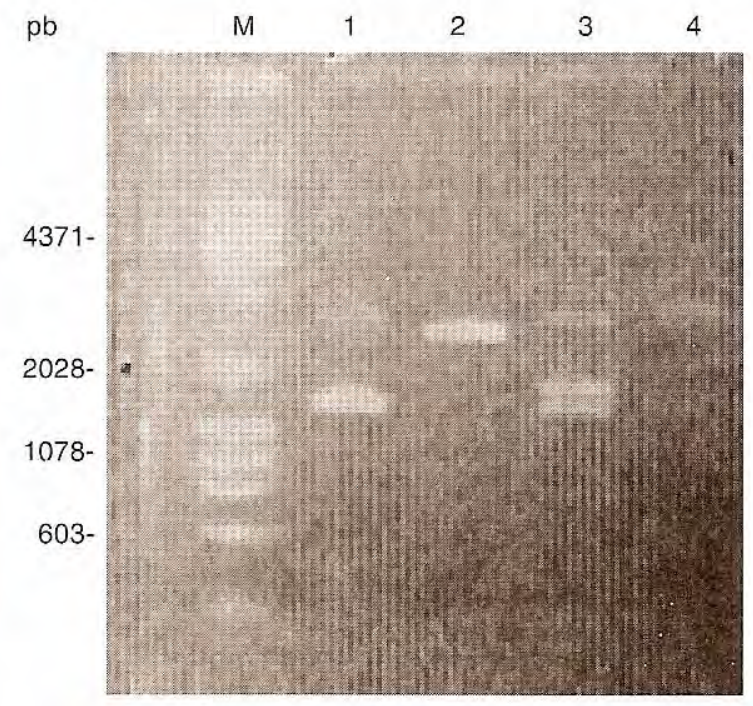

Figura 3. Análisis de restricción, corte con Sca I. Marcador de tamaño (M), pGEM-7Z no digerido (1), pGEM7Z/Sca I(2), clon $\mathrm{J}_{33} /$ Sca I(3), clon $\mathrm{J}_{31}$ /Sca I(4). 


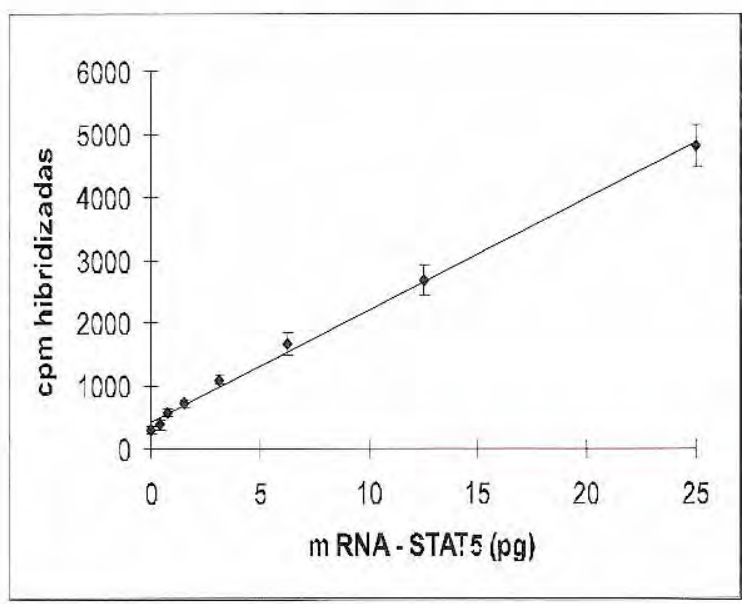

Figura 4. Curva patrón del ensayo de protección con ribonucleasa A. La sonda STAT5 antisentido radiomarcada se hibridizó con cantidades crecientes de patrón de sonda STAT5 sentido. Cada determinación corresponde al promedio de cuatro replicados con su desviación estándar.

muestras de ARN total de hígado y de linfocitos de timo de ratas hembras en condiciones basales.

\section{Discusión}

Para realizar el objetivo de este trabajo de preparar una soncia de STAT5 de rata, hubo necesidad de emplear como materic.' de partida un CADN de STAT5b de ratón por ser, al momento, el único disponible. En el curso de este trabajo se publicó la purificación y clonación de STAT5b de hígado de rata (11), y se estableció una identidad de $98,7 \%$ entre las secuencias de los cADN de STAT5b de rata y de ratón, por lo tanto, continuamos empleando el cADN de ratón como plantilla.

\begin{tabular}{cc}
\hline $\begin{array}{c}\text { Hígado } \\
\text { mARN STAT5 } \\
\text { amol } / \mu \text { g ADN }\end{array}$ & $\begin{array}{c}\text { Linfocitos de timo } \\
\text { mARN STAT5 } \\
\text { amol } / \mu \text { g ADN }\end{array}$ \\
\hline $21,19 \pm 1,27$ & $4,40 \pm 0,18$ \\
$20,70 \pm 1,03$ & $3,89 \pm 0,16$ \\
$15,49 \pm 0,62$ & $5,75 \pm 0,29$ \\
$22,50 \pm 1,35$ & $5,22 \pm 0,31$ \\
\hline
\end{tabular}

Tabla 1. Cuantificación del mARN de STAT5 en hígado y linfocitos de timo de ratas hembras normales $(n=4)$. Cada una de las muestras se analizó en tres niveles de concentración y se indica el promedio $\pm \mathrm{DE}$.
Para escoger la zona a amplificar, se consideró una región en la cual se pudiera discriminar entre STAT1, STAT3 y STAT5, conocidas como blanco de la acción de la $\mathrm{GH}$ en hígado de rata (5). En la región $\mathrm{N}$-terminal existe una zona (aminoácidos 40-200) en la cual divergen las proteínas STAT1, 3 y 5 respecto a la composición de aminoácidos, entonces, se diseñaron los primers para esta zona con el propósito de amplificar una región de $450 \mathrm{pb}$.

En la realización del PCR, se decidió emplear la Vent ADN polimerasa ya que esta enzima posee actividad exonucleasa $3^{\prime} \rightarrow 5^{\prime}$ que resulta en una fidelidad mucho más alta $\mathrm{d} c$ incorporación de bases comparada con la Taq ADN polimerasa que carece de esta función. Sin embargo, esta enzima requiere una optimización más cuidadosa de las condiciones de reacción. Las tres varibles más imporiantes de optimizar son la cantidad de polimerasa, la temperatura de alineación y el nivel de magnesio.

El rango recomendado de cantidad de esta enzima es 1-2 U por $100 \mu \mathrm{L}$ de volúmen de reacción, se decidió emplear $1 \mathrm{U}$ en $50 \mu \mathrm{l}$ de volumen de reacción. Respecto a la temperatura de alineación y teniendo en cuenta los valores de Tm para los primers 5'y 3', se empiearon 55, 60 y $65^{\circ} \mathrm{C}$ en el PC R. La concentración óptima de magnesio que se recomienda para la Vent ADN polimerasa está usualmente entre 2 y 6 $\mathrm{mM}$. Inicialmente, un ensayo con $2 \mathrm{mM}$ de $\mathrm{MgSO}_{4}$ y una temperatura de alineación de $55^{\circ} \mathrm{C} / 1$ minuto, (resultados no mostrados) permitió la amplificación del producto esperado pero acompañado de otros ADN.

Los resultados mostraron (figura 1) que el mejor producto se obtiene empleando una concentración final de $4 \mathrm{mM}$ de $\mathrm{MgSO}_{4}$ y una temperatura de alineación de $65^{\circ} \mathrm{C}$. Por lo tanto, el producto amplificado en estas condiciones se escogió para la clonación. La clonación del producto de PCR se logró con la relación inserto: vector de 40:1, pues así se aisló el clon $J_{33}$ que, en el proceso de caracterización, mostró corresponder al plásmido recombinante esperado. 
La utilización de la ribosonda obtenida en el ensayo de protección con ARNasa o hibridización en solución, para cuantificar el mRNA de STAT5 en hígado y linfocitos de timo de ratas hembras nos permitió establecer que, en condiciones basales, en estos dos tejidos hay expresión del gen de STAT5, correspondiendo un mayor nivel promedio al hígado $(19,97 \pm$ 3,08 ), que a los linfocitos de timo $(4,81 \pm 0,83)$ (Promedio \pm D.S.).

Estudios previos $(5,11,12)$ han evaluado la presencia y activación/fosforilación de la proteína STAT5, empleando las técnicas de Western blot, inmunoprecipitación y ensayos de retardo de la movilidad electroforética. Estos estudios han indicado la presencia pero no la fosforilación de STAT5 en hígado de ratas hembras en condiciones basales. Los resultados que aquí se presentan complementarán estas investigaciones al poder establecer la expresión diferencial del mARN de STAT5 en diversos tejidos.

\section{Agradecimientos}

Los autores expresan su agradecimiento al Programa IPICS, Universidad de Uppsala, Suecia, a Laboratorios Pharmacia \& Upjohn AB, Estocolmo, Suecia, y al Departamento de Química de la Universidad Nacional de Colombia.

\section{Referencias}

1. Darnell JE, Kerr MI, Stark GR. JAK-STAT pathways and transcriptional activation in response to IFNs and other extracellular signalling proteins. Science 1994;264:1415-21.
2. Wood T. Growth Hormone, JAKs and STATs: a model cytokine signal transduction system. Sundbyberg: Larserics Print AB, Sweden; 1996:32-4

3. Liu X, Robinson GW, Gouilleux F, Groner B, Henninghausen L. Cloning and expression of STAT5 and an additional homologue (STAT5b) involved in prolactin signal transduction in mouse mammary tissue. Proc Natl Acad Sci USA 1995;92:8831-5.

4. Innis MA, Gelfand DH. Optimization of PCRs. In: PCR Protocols: A guide to methods and applications. San Diego: Academic Press; 1990;3-12.

5. Ram P, Park S, Choi H, Waxman D. Growth hormone activation of STAT1, STAT3 and STAT5 in rat liver. J Biol Chem; 1996;271:5929-40.

6. Chomczynski $T$, Sacchi $\mathbf{N}$. Single-step method of RNA extraction by acid guanidinium thiocyanatephenol-chloroform extraction. Anal Biochem 1987;162:156-9.

7. Labarca C, Paigen K. A simple, rapid, and sensitive DNA assay procedure. Anal Biochem 1980;102:34452.

8. Lau CF, Sheu SS. Rapid and direct recovery of DNA fragments from agarose gels: an extremely simple method. Meth Molec and Cell Biol 1992;3:190-2.

9. Durnam DM, Palmiter RP. A practical approach for quantitating specific mRNA by solution hybridization. Anal Biochem 1983;131:383-93.

10. Moller C. Aspects of the mechanism of growth hormone action. D (Thesis). Karolinska Institute, Sweden; 1992.

11. Ripperger J, Fritz S, Fey G. Transcription factors STAT3 and STAT5b are present in rat liver nuclei late in an acute phase response and bind Interleukin-6 response elements. J Biol Chem 1995;270:2999830006 .

12. Waxman D, Ram P, Park S, Choi H. Intermittent plasma growth hormone triggers tyrosin phosphorylation and nuclear translocation of a liverexpressed STAT5-related DNA binding protein. J Biol Chem 1995;270:13262-70. 